\title{
The Potential of Digitalization in Management Accounting and Control in German Energy Supply Companies
}

\author{
Lisa Wunderlich \\ University of Duisburg-Essen, Chair for Business Administration and Management Accounting \& \\ Control, Duisburg, Germany, E-Mail: lisa.wunderlich@uni-due.de \\ Prof. Dr. Andreas Wömpener \\ University of Duisburg-Essen, Chair for Business Administration and Management Accounting \& \\ Control, Duisburg, Germany, E-Mail: andreas.woempener@uni-due.de
}

\begin{abstract}
Due to continually decreasing profits in the commodity business, German energy supply companies (ESCs) find themselves under increasing pressure to act in order to ensure their longterm existence. The Management Accounting \& Control department (MAC) as well as modern technologies are able to provide promising solution approaches to these issues. To gain an overview of the extent and content of the current usage of digital instruments in the MAC, the implementation possibilities of different technologies for the most resource-intensive MAC processes are being identified as part of a research project conducted by the University of Duisburg-Essen in Germany. Based on this, concrete application examples in German ESCs are elaborated and analyzed using expert interviews. First results of this research are being shown in this paper. It appears that influencers are needed to establish a common understanding of digitalization, overcome rugged system landscapes and inform, sensitize and motivate employees to use digital technologies. The applicability of different technologies can be visualized and communicated using a multi-dimensional radar chart as elaborated within this research project.
\end{abstract}




\section{Table of Contents}

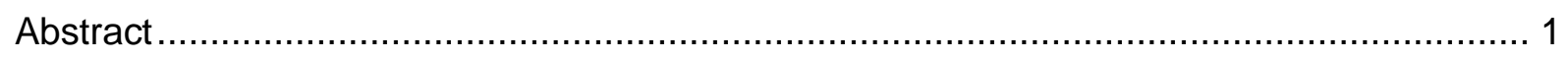

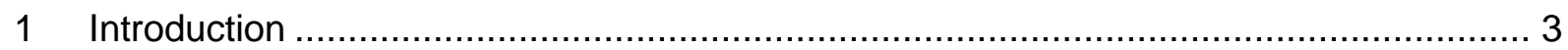

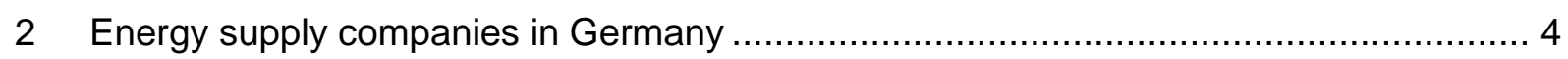

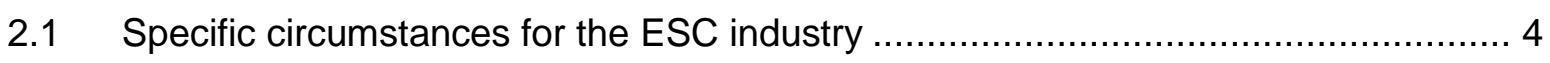

2.2 Management Accounting \& Control in ESCs ..................................................... 5

3 Identification of possible impacts of digitalization on MAC ................................... 6

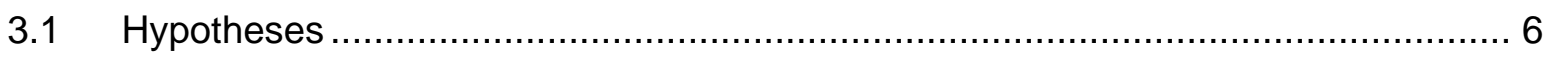

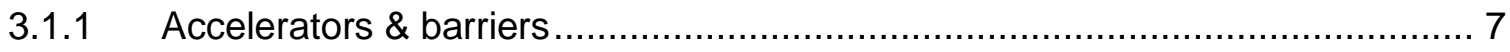

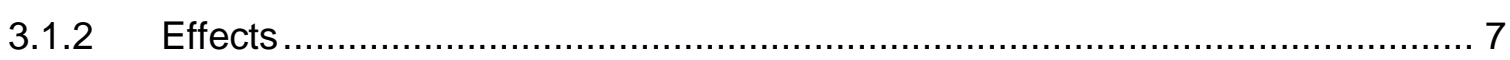

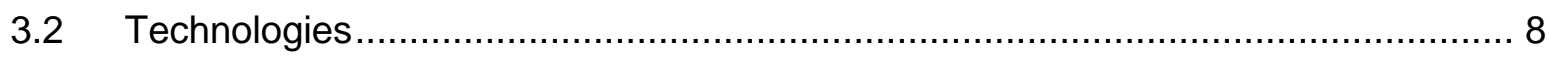

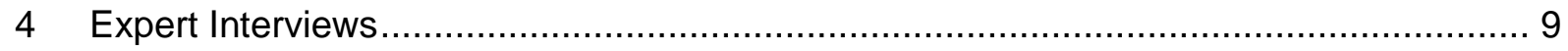

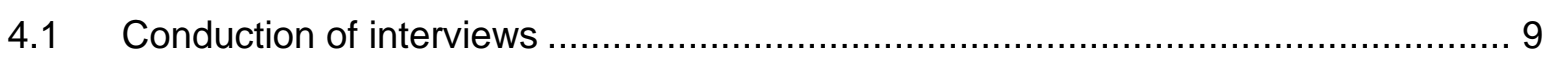

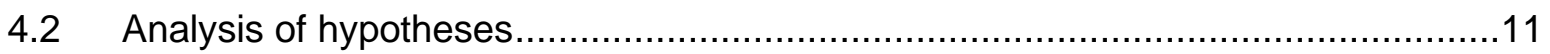

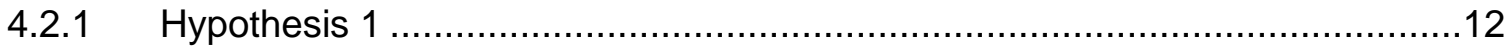

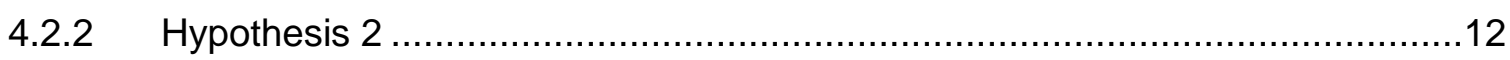

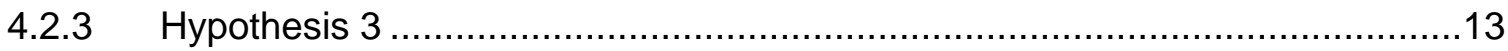

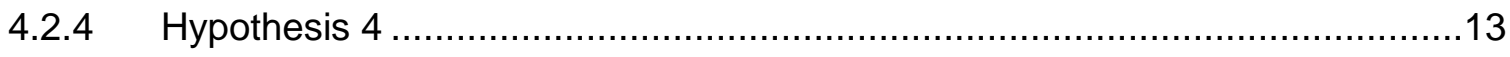

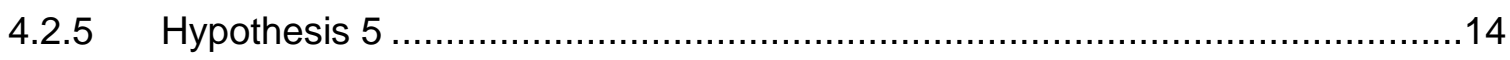

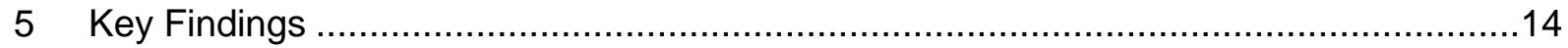

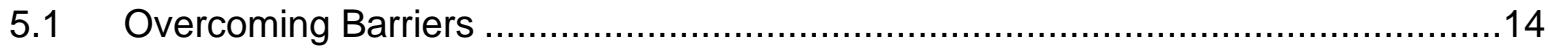

5.2 Opportunities of Benefiting from these Effects ...........................................16

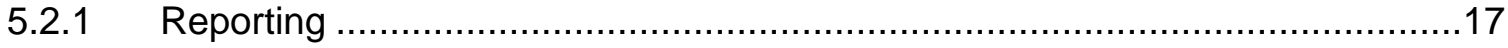

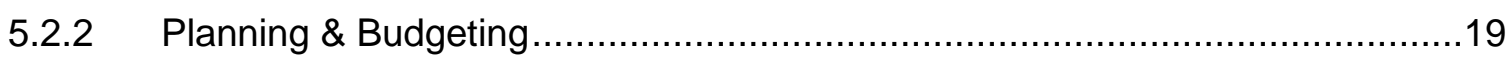

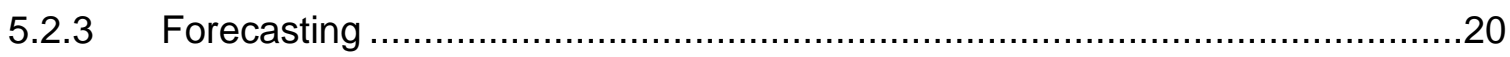

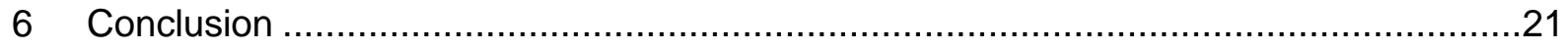

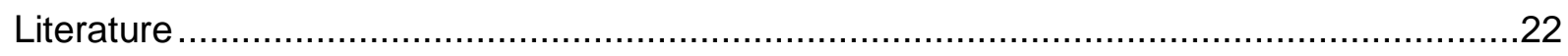




\section{Introduction}

At least since the liberalization of the German electricity market (enacted by an amendment to the Energiewirtschaftsgesetz) as well as the German plan to abandon nuclear energy in 2011, energy suppliers have been confronted with an increasing, partly even ruinous price war on each (unregulated) stage of their value-added chain (Doleski, 2017, pp. 3-4). This even caused a public utility supplier (Stadtwerke Gera) and a local energy supplier (BEV) to file for insolvency. Even global players such as $E n B W$ or $E . O N$ had to file losses for several accounting periods (Dierig \& Wetzel, 2016; Knapp, 2019).

At the same time, the progress of digitalization - sometimes referred to as the 'Fourth Industrial Revolution' - has initiated another very drastic change throughout all sectors. The new possibilities resulting from digital interconnectedness and data processing offer new opportunities for energy suppliers but also additional risks (Fabritius \& Fischer, 2019, p. 5).

Management Accounting \& Control (MAC) represents an increasingly significant corporate function and can therefore act supportively in overcoming these challenging changes. It is unclear in this context, to what extent the functions and roles of MAC departments are re-shaped in order to successfully handle this changing reality, while heterogenous environments and MAC job profiles make it difficult to describe and analyze this evolutionary process.

As part of a research project at the Chair for Business Administration and Management Accounting \& Control at the University of Duisburg-Essen, the project investigates whether and to what extent digitalization influences MAC functions as well as the respective business model. These questions are being answered by an analysis of expert interviews. This article provides first insights into the current state of research, from which management accountants and digitalization officers in energy supply companies can derive valuable conclusions.

Chapter 2 will begin with demonstrating the specific circumstances of the energy supply sector in Germany (section 2.1) and the resulting particularities for the MAC in energy supply companies (section 2.2). After this, chapter 3 will identify possible impacts of digitalization on MAC aspects and formulate hypotheses about which accelerators and barriers of digitalization can be found within MAC and which effects can arise for the functions of MAC due to the digitalization (section 3.1). Additionally, technologies will be introduced that have a high impact on MAC processes (section 3.2). These deductively derived results will be verified or declined using expert interviews (chapter 4), before first findings regarding the overcoming of barriers (section 5.1) and opportunities of benefiting from the effects of digitalization on MAC processes (section 5.2) are being shown. Finally, chapter 6 will conclude this paper, which will also include limitations and a further research outlook. 


\section{Energy supply companies in Germany}

\subsection{Specific circumstances for the ESC industry}

The energy supply is subject to special circumstances due to the particularities of the product energy ${ }^{1}$. One of these particularities is the strong interplay between the energy economy and politics: Firstly, the companies within the ESC industry are committed to a mandatory supply assignment as part of $\S 1$ Energiewirtschaftsgesetz (EnWG). Therefore, they are unable to make all their business decisions in an economically and technically most beneficial manner, as they are forced to provide the energy as requested and needed by the consumer an an time. Moreover, ESCs find themselves in an environment that has been and still is subject to radical changes due to political interventions. Of special importance in this regard is considered the EU market liberalization in 1998 which led to a breakage of the previously governmentally regulated supply chain, so that it became accessible to the whole competitive field (blue boxes in figure 1). Thereby, a paradigm shift of the energy supply was initiated (Oesterwind et al., 1996, p. 9). ${ }^{2}$

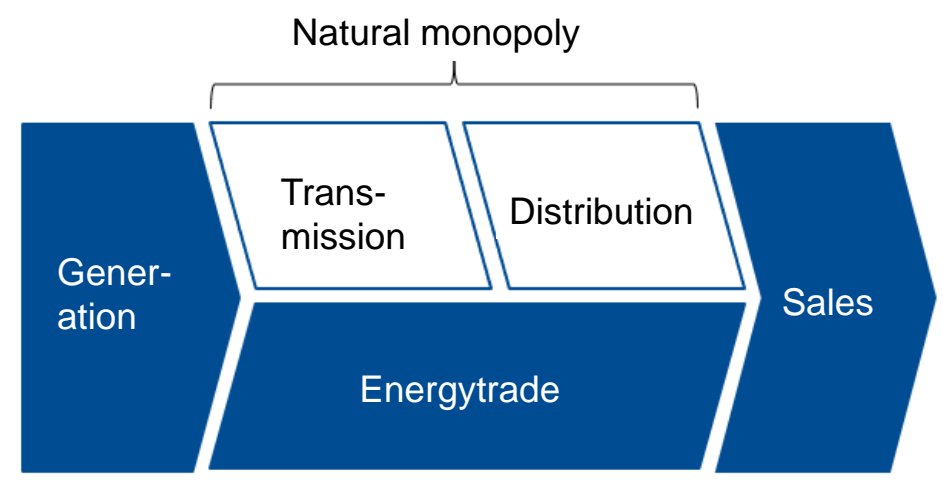

Figure 1: Supply chain of ESCs (based on Oesterwind et al. (1996, pp. 75-76).

Since the nuclear catastrophe in Fukushima, Japan in 2011 and the energy transition resulting therefrom, stating that nuclear energy is to be abandoned in Germany until the end of 2022 at the latest, an increasing number of renewable energy source plants ist added to the network, leading to an excessive stress of the supply system. The physical necessity of providing exactly the requested amount of electricity at any time has therefore become a lot harder to fulfil (Elsner et al., 2015, p. 15).

Energy that is provided by energy supply companies, is differentiated into electricity, gas, and the supply of heat and cold. (Statistisches Bundesamt, 2008, p. 102) Within this research, this further categorization is not made use of.

2 The operation of supply networks (transmission and distribution) is still considered a natural monopoly and has therefore been excluded from the market liberalization. 


\subsection{Management Accounting \& Control in ESCs}

Due to the particularities of the industry as shown in section 2.1, the traditional and common MAC approaches resulting from the production theory do not possess their full validity for energy supply companies. Most closely, the MAC in ESCs is related to the MAC within the services industry since the products in this sector are defined by their immateriality, irreversibility, integrability and individuality - as an opposite to tangible goods. Immateriality points out the difficulty of identifying a fixed price of energy due to its intangible character since the good is hardly storable and must be delivered to a location, where offer and request meet. Irreversibility means that energy ${ }^{3}$ that has once been used cannot be given back. The term integrability identifies the customer to play the most elementary role in the provision of the service. Without his request, the service cannot be performed and - due to its lack of storability - also not be used in an alternative way. Another important characteristic of a service is its individuality (Irrek, 2004, pp. 30-35). For the case of ESCs, it has to be considered that energy is classified as a qualitatively homogenous commodity product that does not contain any possibility of differentiating the supplier from its competitors. Instead, the price is the main criterium of choice for the customer (Kirschen \& Strbac, 2004, pp. 49-50). Additionally, this price is subject to strong fluctuation at the stock exchange. An ESC must therefore seek other opportunities to stand out against its competitors regarding its individual products offered in other business fields - for example through services that go far beyond the sole supply with energy.

In opposite to the typical companies of the services industry, the interconnection with politics and the technical particularities must be taken into consideration. Moreover, the companies have been dropped into a market weave following the (partly) liberalization which they were not used to beforehand and which leads to a change of company strategies. The customer and value centricity must now be on the agenda and are getting into the strategic focus and require a fundamental change within the companies, deeply influencing the MAC. The MAC in ESCs is therefore confronted with challenges similar to other conduction-based and formerly regulated industries, such as the telecommunication sector (Landgrebe, 2006, pp. 24-25).

Summarized, those are:

- the more complicated assessment and control of production costs,

- the excessively high share of overhead expenses (that cannot be assigned directly to a specific product),

- the combination of high standby costs and fluctuation/hardly predictable request,

- while being obliged to ensure the supply at any time and

3 The authors do recognize that energy is not being consumed physically, but rather just changes its form of state. As part of the provision of services by an ESC, the term used here refers to the purchase and payment of energy as conducted by the customer, resulting in the energy not being available for further sale afterwards. 
- the support in the development of new business models since the energy supply service itself does not contain any unique selling prepositions.

In order to enable a deeper dedication to these particular questions of the MAC in ESCs, it is of high interest to digitalize these MAC processes that are resource-intensive and show a periodic request. These MAC processes with a high digital potential include Reporting, Planning \& Budgeting as well as Forecasting (Nasca et al., 2018, pp. 80-86). ${ }^{4}$

\section{- Reporting}

With the use of reports, the management is to be supported in its decision making and led to conduct useful measures.

\section{- Planning \& Budgeting}

Using a planning that is oriented towards the company's strategic goals, available resources are to be assigned in a most efficient manner, in order to achieve the strategic aims.

\section{- Forecasting}

The forecast should identify deviations from the formulated plan in time, analyze them and - most ideally - initiate countermeasures.

\section{Identification of possible impacts of digitalization on MAC}

\subsection{Hypotheses}

Due to the particularities of the ESC industry (see section 2.2), the MAC tasks are subject to special conditions and universal statements on the impacts of digitalization on the MAC only possess a limited validity. In order to elaborate these differences, literature of (cross-industry) relevance is being analyzed to extract common opinions and understandings regarding the topics of digitalization and the digitalization related to (cross-industry) MAC tasks. From these, hypotheses for the ESC industry are to be derived.

These hypotheses $(\mathrm{H})$ can be classified into two categories: ${ }^{5}$

- Accelerators \& barriers of digitalization within MAC

- Effects of digitalization on the MAC functions

\footnotetext{
$4 \quad$ Nasca et al. (2018) also name Accounting (data management) as a relevant MAC process. Nevertheless, this does not represent a MAC function according to the comprehension underlying this paper and is therefore not taken into consideration.

5 All hypotheses refer to the ESC industry, even if not explicitly named.
} 


\subsubsection{Accelerators \& barriers}

It is of outstanding interest to elaborate if digitalization efforts in companies of the ESC industry are increasingly initiated and which motivations can be identified for this (and also what hinders companies from implementing such technologies).

In order to investigate this question, three hypotheses have been stated:

H1) A major obstacle to the digitalization in companies is that employees and executives typically lack knowledge of the its opportunities.

Since there is no clear definition of the term digitalization or a universal listing of implementation opportunities, most executives and MAC employees do not really know, which advantage recent technologies can deliver to different business areas. Therefore, an implementation is often not even considered.

H2) The increasing appearance of digitalization efforts in companies is supported and accelerated by external impacting factors, such as revenue drops or law amendments.

As the appearance of MAC in ESCs has drastically changed since the market liberalization and the value centricity resulting from this, deep and resource-intensive measures are mainly conducted within this transition. The digitalization does not have the priority in this regard. Only when it becomes necessary due to external factors, such efforts are being implemented.

H3) The benefit of digitalization is primarily recognized in business areas with direct customer contact, which leads to internally acting MAC departments being left behind in this regard.

Since MAC is considered an internal business area that does not generate an (obvious) revenue, resource-intensive implementations of new technology are only conducted in departments that contain a clear (measurable) benefit, e.g. in the sales department with the objective of gaining more customers.

\subsubsection{Effects}

In case a company has made the decision to implement new technology within its MAC department, it is of high interest, which effects this will have on the MAC itself. Regarding this question, two hypotheses are being investigated: 
H4) The activity field of a MAC employee will change long-term.

Due to the various technological and regulators changes, the structure of MAC tasks in ESCs will undergo a drastic transition since repetitive tasks will disappear and more time will remain for analyses and interpretations. In this regard, it has to be assumed that some posts that have formerly taken over purely repetitive and therefore automatable activities will be eliminated, which causes a certain fear of digital measures.

H5) Through the possibilities of digitalization, MAC can support in the process of developing new business models, in order to satisfy the tertiarization and changed customer demand resulting from this.

Due to the necessity of offering their customers products and services that go beyond the pure supply of energy, they must steadily develop new products and expand their business model. MAC can act supportively since it is enabled to expand its role as a management consultant and provide rational support due to the transition of its capabilities (according to $\mathrm{H} 4)$.

\subsection{Technologies}

In order to be able to meet the altered requirements of customers and shareholders, MAC has to adapt to the described challenges and changes while assessing the concrete value of a digital technology. The most common technologies in this respect are Big Data, Business Analytics and Robotic Process Automation (RPA) (Langmann, 2019, p. 10). ${ }^{6}$

\section{Big Data}

Big Data describes a large amount of data that cannot be dealt with using conventional information systems. This technology combines techniques to analyze, manage and store data (Bhimani, 2015, pp. 66-67). Because increasing amounts of data accumulate (e. g. amount and time of energy consumption), energy suppliers can develop new business models.

\section{Business Analytics}

To secure rationality, a company has to use available data to generate new knowledge about their customers and shareholders as well as stakeholders. Business Analytics helps to understand what has happened and why it has happened (descriptive) as well as what will happen

Langmann (2019) also names Machine Learning as a relevant technology. Machine Learning describes an automated process that can extract patterns from data (Kelleher et al., 2015, p. 5). Accordingly, we do categorize this as a supportive tool of Prescriptive Analytics and not as an independent technology. 
(predictive, using machine learning and neural networks) and why it will happen (prescriptive) to automatically generate recommendations for certain measures (Bolt, 2015, pp. 674-675).

\section{Robotic Process Automation}

RPA is a collective term for tools interacting with user interfaces of computers like a human being would do. Thereby, processes can be automized that have so far been manually edited by a person. MS Excel ${ }^{\odot}$ macros can be considered a first step of RPA (yet with manual acting). In a later phase, RPA, in combination with machine learning or Al, can solve problems automatically based on recognizable patterns (Manutiu, 2018, p. 5).

\section{Expert Interviews}

\subsection{Conduction of interviews}

To gain extensive insights into ESC's general practices as well as the opinions and impressions of accountants working for these companies, 26 semi-standardized interviews ${ }^{7}$ with 29 experts from 19 companies with a total duration of approximately 30 hours have been conducted between July 2018 and April 2019. Of these 19 companies, 16 operate in the Generation (G) sector, 16 in Trade and Sales (T/S) and 6 companies are Distribution system operators (D) ${ }^{8}$ The companies involved in these interviews are spread all over Germany (see Figure 2) and can be divided and classified as shown in Table 1.

In accordance to a company's scale and structure (especially in classes 1 and 2, see Table 1), several interviews in the same company have been conducted in order to gain insight into different sections and departments (on corporate as well as on peripheral levels). The total number of 29 interviewees can be differentiated as follows:

- 14 heads of (decentralized) MAC departments or accounting employees (group 1)

- 7 corporate managers of the finance or MAC function (group 2)

- 8 CEOs or heads of corporate development and digital projects (group 3).

7 The choice of method and conduction of the survey was made using the classification of Gläser and Laudel (2010, pp. 38-43).

8 The classification is established according to categories 35.11 to 35.14 of the classification of economy sectors by the German Federal Office of Statistics (2008, p. 102). If an ESC is active in more than one sector, it is counted multiple times. The sector Transmission (category 35.12 ) is not included in this research due to the small number of acting companies, in order to ensure anonymity. 


\begin{tabular}{|c|c|c|c|c|}
\hline \multirow{2}{*}{ Class } & \multirow{2}{*}{ Label } & \multirow{2}{*}{ Description } & \multicolumn{2}{|c|}{ Number of } \\
\hline & & & companies & interviews \\
\hline 1 & $\begin{array}{l}\text { Big corpo- } \\
\text { ration }\end{array}$ & $\begin{array}{l}\text { - Large corporations, operating internationally/nation- } \\
\text { wide } \\
\text { - Net sales > } 10 \text { bil. } € \text { p. a. and > } 10.000 \text { employees } \\
\text { - Several shareholders due to spread ownership or } \\
\text { holding structures } \\
\text { - Operating in all business stages (G, D, T/S) }\end{array}$ & 5 & 10 \\
\hline 2 & $\begin{array}{l}\text { Medium } \\
\text { scale ESC }\end{array}$ & $\begin{array}{l}\text { - ESCs operating nationwide but with regional focus } \\
\text { - Net sales 1-10 bil. } € \text { p. a. and 1.000-10.000 employees } \\
\text { - Shares are mainly held by municipal institutions } \\
\text { - Operating in all business stages (G, D, T/S) }\end{array}$ & 5 & $7^{*}$ \\
\hline 3 & $\begin{array}{l}\text { Smaller } \\
\text { (traditional) } \\
\text { municipal } \\
\text { supplier }\end{array}$ & $\begin{array}{l}\text { - ESCs with a strong regional/municipal orientation } \\
\text { - Net sales < } 1 \text { bil. } € \text { p. a. and }<1.000 \text { employees } \\
\text { - Shares are nearly exclusively held by municipal insti- } \\
\text { tutions } \\
\text { - Potentially not operating in all business stages (e. g. } \\
\text { no own central plant units) }\end{array}$ & 7 & $7^{* *}$ \\
\hline 4 & $\begin{array}{l}\text { Energy } \\
\text { services }\end{array}$ & $\begin{array}{l}\text { - Allocation to other categories not possible } \\
\text { - Exclusive focus on T/S } \\
\text { - Regional allocation not possible }\end{array}$ & 2 & 2 \\
\hline
\end{tabular}

Table 1: Classification of interviewed companies and interviewees ${ }^{9}$

9 * One relevant interview has been conducted with two interviewees;

** One relevant interview has been conducted with three interviewees. 


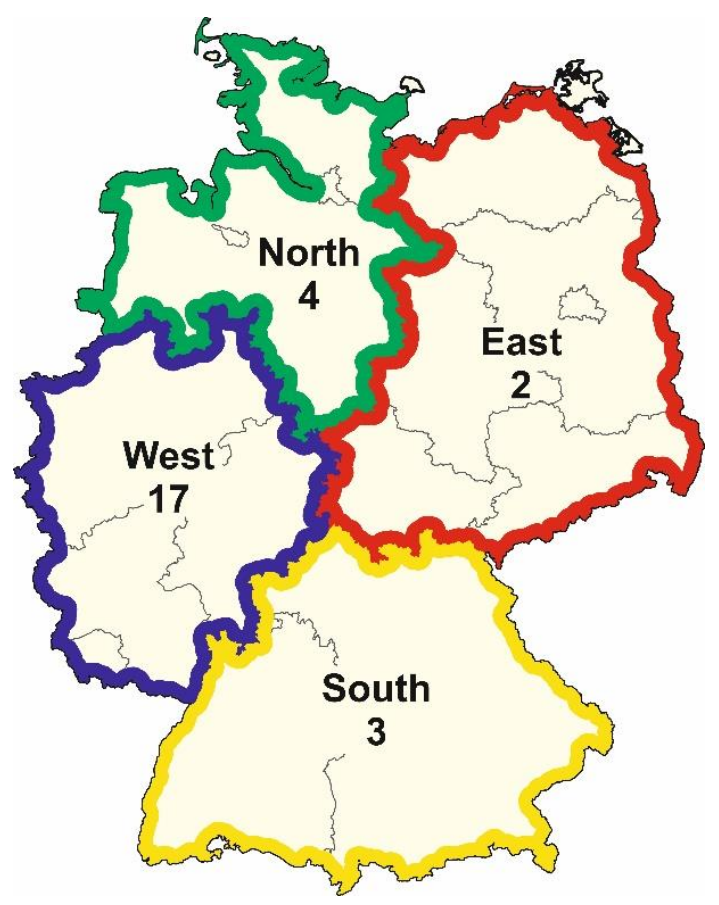

Figure 2: Number and geographical spread of interviews in in each region of Germany (own image)

\subsection{Analysis of hypotheses}

The interviews have been evaluated using a qualitative content analysis according to Mayring (2015, pp. 50-109). Corresponding to the statements as made by the interviewees, the interviews have been assessed ${ }^{10}$ regarding their agreement $(A)$, denial $(D)$ and partly agreement/denial $(P)$ of the hypotheses (see Figure 3). In this context, it is of high interest, whether ESCs in Germany have already recognized the recent challenges and decided for technological innovations.

10 The hypotheses have not been directly interrogated during the interviews, but rather the interviewee's opinion has been derived from the overall context of answers. 


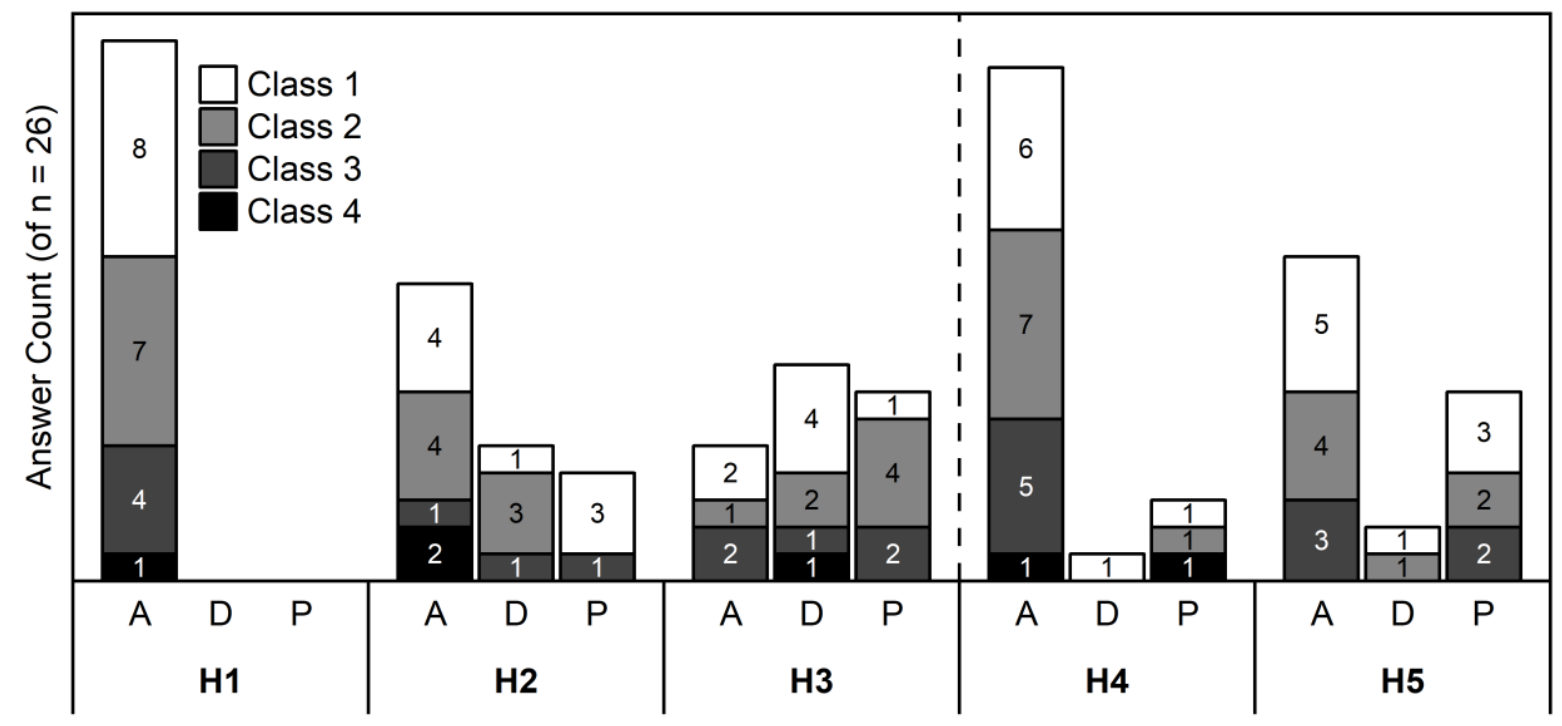

Figure 3: Interview results ${ }^{11}$

\subsubsection{Hypothesis 1}

The approval of this hypothesis over all classes is obvious. Most experts consider it highly problematic that there is no common understanding of what digitalization means precisely and what benefits it holds, which hinders a useful implementation of technologies. Especially since most employees and executives think of digitalization as a 'buzzword' they come across in each perspective of their life (both personal and business), they easily feel overwhelmed and consider many digital incentives are only started because they are labelled 'digital', without a clear strategy and purpose. Nevertheless, many of the interviewed experts, especially executives, increasingly recognize the possible chances new technologies hold, and therefore see it as their duty to motivate their employees for these topics.

\subsubsection{Hypothesis 2}

This hypothesis generally finds the interviewees' (full or partly) agreement since many have already experienced revenue drops in their companies and the corresponding cost reduction measures. These measures particularly include steps towards automatization ("We must become more efficient as our gains shrink." ${ }^{12}$ ). Mainly, these automatization efforts are focused on the accounting tasks, which leads to MAC generally not being connoted with automation (that is partly considered equal to digitalization, see $\mathrm{H} 1$ ).

11 If no exact classification of the answers of an interviewee (neither to A, D nor $P$ ) is possible, this interview is not represented in the respective hypothesis.

12 Statement of an interviewee from group 3, class 1. Note: All interviews were conducted in German. Therefore, given quotes are translated by the authors. 
At the same time, ever-changing regulations such as the nuclear exit or the Law of Digitalizing the Energy Transition (GDEW) force the suppliers to reconsider their behavior since "manually implementing everything would take legions"13. Digital initiatives can help transforming their business model and prepare for the transition. Nevertheless, some experts state that many of these initiatives do not represent part of a well thought strategy, but are rather just being conducted for the sake of doing it.

\subsubsection{Hypothesis 3}

The acceptance of this hypothesis in class 1 can be explained by the fact that two of the companies interviewed are already pursuing a digitalization strategy in the MAC or financial department. Two more have just created a position with the aim of establishing such a strategy and systematically bundling projects that have already been implemented in the company decentrally. Hence, especially big corporations have recognized that management accountants may function as coordinators and change agents because the financial components of such transformational processes (in the organizational perspective as well as task-related) cannot be disregarded. On the other hand, most experts claim that the financial department remains in the background and is considered an "auxiliary element" 14 because the companies do not see the immediate amortization and are skeptical of investing in times of crises. Furthermore, most can only imagine investing in areas that directly create measurable value.

Additionally, class 2 and 3 companies are stating that reliability is a big issue. They see themselves as a reliable partner of the citizens of their supplied cities and are afraid of failures causing a loss of customers' trust and in consequence, their USP. Hence, they will not digitalize their processes in the MAC and financial departments for the fear of loss of reliability. Class 4 interviewees do not see any (further) need to pursue digitalization strategies in the MAC department because it is already lean due to their business model.

\subsubsection{Hypothesis 4}

There is a broad acceptance across all classes of companies and interviewee groups that things will change over the next years. Mostly, because repetitive tasks will be automated, leading to increased time to focus on a management accountant's core competences. There is also word of a reinforced corporation with the company's management and therefore a transition in the management accountant's role. It is unison opinion, that "flexibility when it comes

\footnotetext{
13 Statement of an interviewee from group 1, class 3.
}

14 Statement of an interviewee from group 2, class 3. 
to the task area"15 is needed. On the contrary, one interviewee stated, that "a classical MAC will still be needed and must even be deepened. [...] A cobbler should stick to his last."16 or "There is not possibility that a robot could be able to manage such things." 17

Regarding the changes of activity fields, there is a broad unity about an imminent change of the magnitude of MAC departments. This does not directly come with fear but is rather categorized as inevitable in order to face future challenges. Regarding the reduction of jobs, experts also often refer to the social component, especially in companies that are mainly or exclusively held in public ownership (classes 2 and 3), stating a reduction must always happen in a most socially responsible manner, making use of further education measures or retirement. At the same time, this results in the opportunity of counteracting current and future shortages of skilled employees with the help of digitalization.

\subsubsection{Hypothesis 5}

Nearly all experts do think that ESCs must transform their business model and dynamically adapt it to environmental circumstances in order to stand out against their competitors and the increasing number of suppliers within their own provision field. ${ }^{18}$ This is expressed in a particularly drastic manner by one interviewee, stating that "all energy supply companies are fully run down with their current business model"19. Concepts of offering new (digital) and customercentric services, range from Smart Home-solutions to supporting electric mobility and on to real estate management. MAC can act supportively herewith, help the management in developing new business models and thereby further enhance its capabilities.

\section{$5 \quad$ Key Findings}

\subsection{Overcoming Barriers}

For simplifying the implementation of digital technologies in MAC departments within ESCs, the previously identified accelerators are to be favored and the barriers are to be overcome (see section 3.1.1).

\footnotetext{
15 Statement of an interviewee from group 3, class 1.

16 Statement of an interviewee from group 3, class 2.

17 Statement of an interviewee from group 1, class 3.

18 The number of electricity suppliers amounted to more than 100 in $72.2 \%$ of all German network areas in 2018. In only seven years, this share has more than tripled (Bundesnetzagentur \& Bundeskartellamt, 2020, p. 268). This shows the high number of possible competitors to one single ESC.

19 Statement of an interviewee from group 2, class 2.
} 
In order to tackle the most obvious barrier - the common disagreement on what digitalization is $(\mathrm{H} 1)$ and how it can be used in energy supply companies and their MAC departments - a definition and differentiation of the domain is proposed.

First a differentiation between digitization and digitalization is suggested. The former describes a transformation from analogous objects into the corresponding digital representation with information being separated from a physical carrier and converted into a digital model of binary digits. Ergo, digitization represents the purely technological perspective, whereas digitalization generally uses this digital model to additionally cover economic and social dimensions. The digital model allows the use of interconnected computers and automation ${ }^{20}$ to add to the company's value, allowing it (or the MAC department respectively) to become more resource efficient, which in turn affects the economical perspective. In order to properly understand and work with digital models, employees have to undergo a learning process. This affects the social dimension and can be described as digital transformation because it requires a structural and organizational change of the functions affected as well as an adapted job profile for those working with these models (Legner et al., 2017, pp. 301-302) (see Figure 4 for a summary of these definitions).

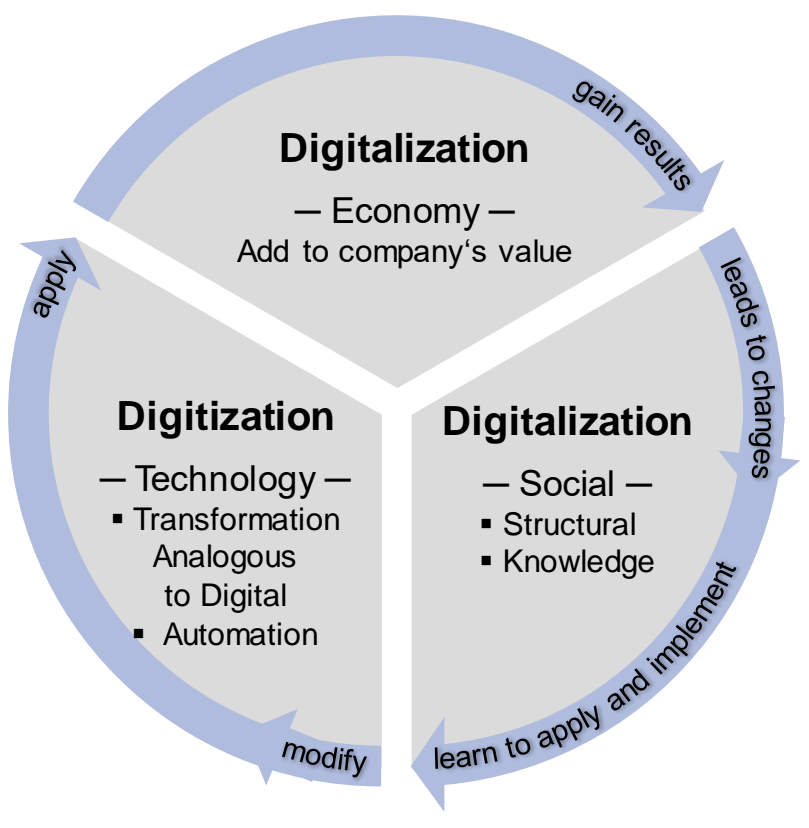

Figure 4: Digital transformation process (own image)

20 In this context, automation means generating digital models automatically because the problem to be solved has a structured and repetitive pattern. Such problems can mainly be found in the area of accounting. The next level would be to use artificial intelligence $(\mathrm{Al})$ to solve even less structured and non-repetitive problems which would then also refer to MAC issues. 
When it comes to the transformation of analogous data, a rugged system infrastructure (especially after mergers and acquisitions) is a major barrier that hinders a systematic modelling of the structure and repetitive processes within a company or department respectively. Ergo, synchronizing and implementing all available data is expensive and contradicting omnipresent compulsory corporate cost-cutting programs. Furthermore, for implementing a digital strategy, additional personal effort is indispensable as most employees are working at their capacity limit. This comprises another barrier. Consequently, MAC departments need some (internal or external) influence that will lead the way and provide resources, in order to start digital initiatives. This can for example be a requirement of the shareholder(s) (e. g. a city implementing a digitalization strategy and demanding all its investments to do alike) or a proactive employee or executive thriving in this idea and collecting the necessary funds, elucidating and motivating co-workers and executives and continuously pushing the idea forward against all odds.

\subsection{Opportunities of Benefiting from these Effects}

Regarding the effects identified in section 3.1.2 that can arise due to the digitalization of MAC departments in ESCs, it has to be determined whether these could be seen advantageously and to what extent the technologies identified in section 3.2 are impacting the most relevant MAC processes (see section 2.2), according to the experts' opinion (see chapter 4).

In order to transparently demonstrate the impacts of the identified, a radar chart is used in which several dimensions are depicted from a center point. ${ }^{21}$ Based on the interviews, five dimensions have been identified to be displayed in the chart. These are the most common points that will either support or impede the implementation of technologies: ${ }^{22}$

\section{- Costs:}

What are the costs of implementing the technology?

\section{- Know-how:}

How much (technical) knowledge is required to implement and run the technology? If employee training or external consultants become necessary, how will this influence the costs?

21 Further information on this illustrating instrument can be found in Harris (2000, pp. 320-322).

22 These dimensions are not fully independent from each other. 


\section{- Acceptance:}

To what extent will employees and executives accept and adopt the technology? Do they possess resentments against the implementation as their fear losing their jobs?

\section{- Reliability:}

How reliable is the technology when it comes to error rate and failure safety? Can the employees test the system themselves to verify the results?

\section{- Impact on MAC:}

How much will the implementation affect the MAC department? Will it change the organization, role and competences?

The scales are divided into 'high', 'middle' and 'low' as there are no quantitative measures for the dimensions chosen. ${ }^{23}$ Shown below is a radar chart for the three MAC processes of interest, to demonstrate the radar chart. Figure 5 shows the reaction of Reporting when either Big Data, Business Analytics or Robotic Process Automation (see section 3.2) are to be implemented; Figure 6 for Planning \& Budgeting and Figure 7 for Forecasting. This can aid management accountants in energy supply companies that debate whether to implement digital technologies or not and which might suit their circumstances and desired tasks best.

\subsubsection{Reporting}

Reports should generally suit the addressee as good as possible, be available quickly and be based on real-time data. This can hardly be satisfied when reports are generated manually. Therefore, the different technologies contain a significant benefit.

If models using Big Data are implemented, this is associated with (relatively speaking) fairly low costs and know-how. The data (normally) already exists in energy supply companies; it just has to be made available and processed. Thus, this technology will find the employees' approval as it takes away tasks that are of high repetitive character and are therefore usually not fancied. The technology will even eliminate the human factor and reduce mistakes. The impact on MAC in this context is average as it will only make data available that needs to be worked with in another aspect. Yet, it is the foundation for all other technologies. Big Data can only systematically be used if the data basis is synchronized and there is no rugged system infrastructure. Therefore, the implementation is easier for smaller (class 3 ) than bigger (class

23 Theoretically, the cost axis could be filled with concrete values. Nevertheless, as this is always strongly dependent on the company's magnitude and the technology depth chosen, this is waived here. 
1) companies. Nevertheless, due to the financial possibilities and manpower, such strategic projects are more easily realized in class 1 (and 2) companies.

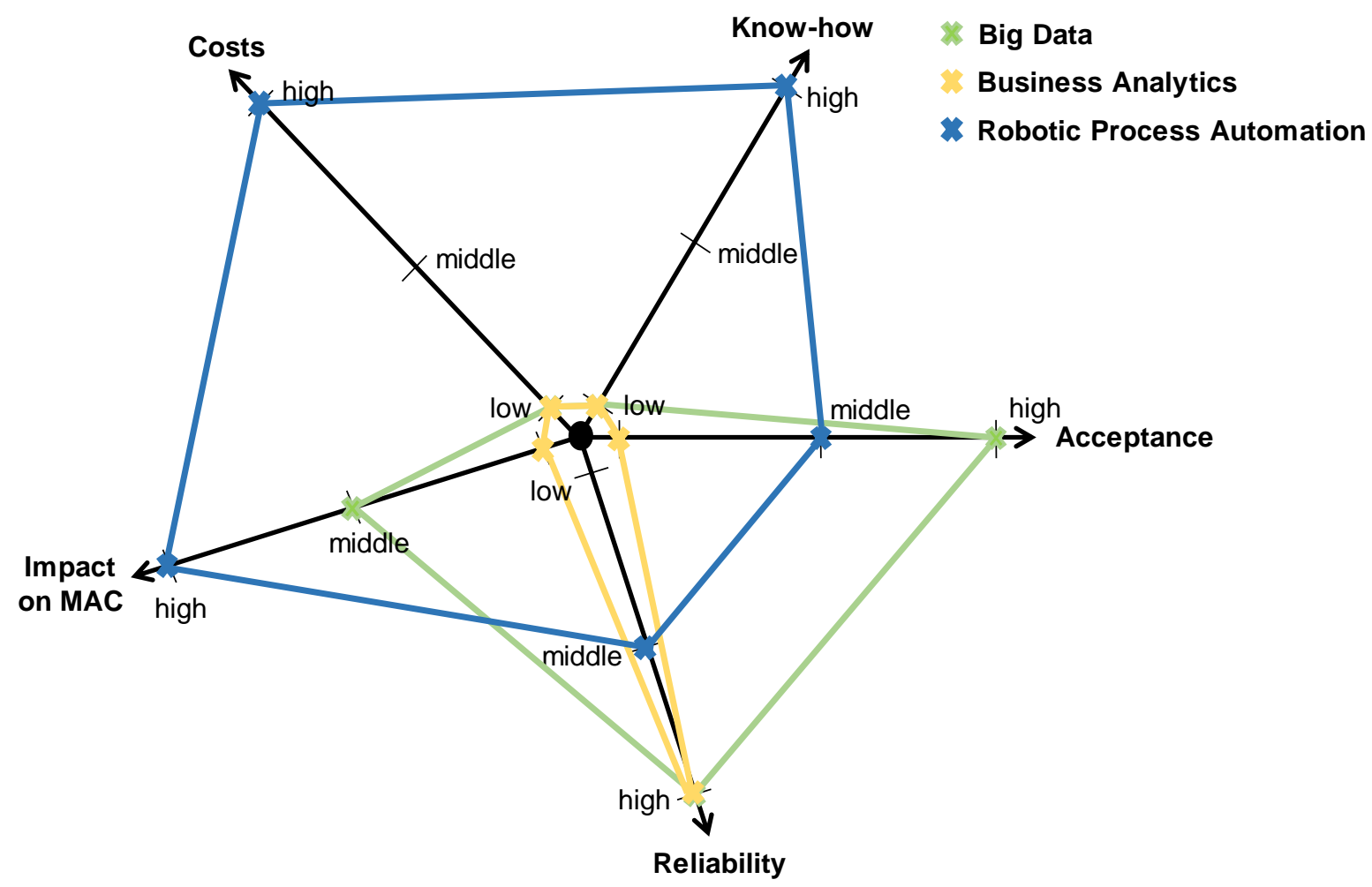

Figure 5: Radar chart for Reporting (own image)

On the other hand, Business Analytics hardly impacts MAC as it does not change the reports itself. Still, it allows to provide more targeted information for different addressees. Due to the insignificant changes, the costs, know-how, acceptance and reliability do not differ much from those results concerning Big Data.

The literature review reveals that RPA has the biggest impact on reporting when it comes to digital technologies because reports are generated more easily, automatically and faster even when unexpected incidents occur. Due to these benefits it is widely accepted in companies, yet its' results can not necessarily be verified and therefore employees might hold some reserve. Obviously, the more complex a technology is, the more expensive and difficult it is to be implemented and run. 


\subsubsection{Planning \& Budgeting}

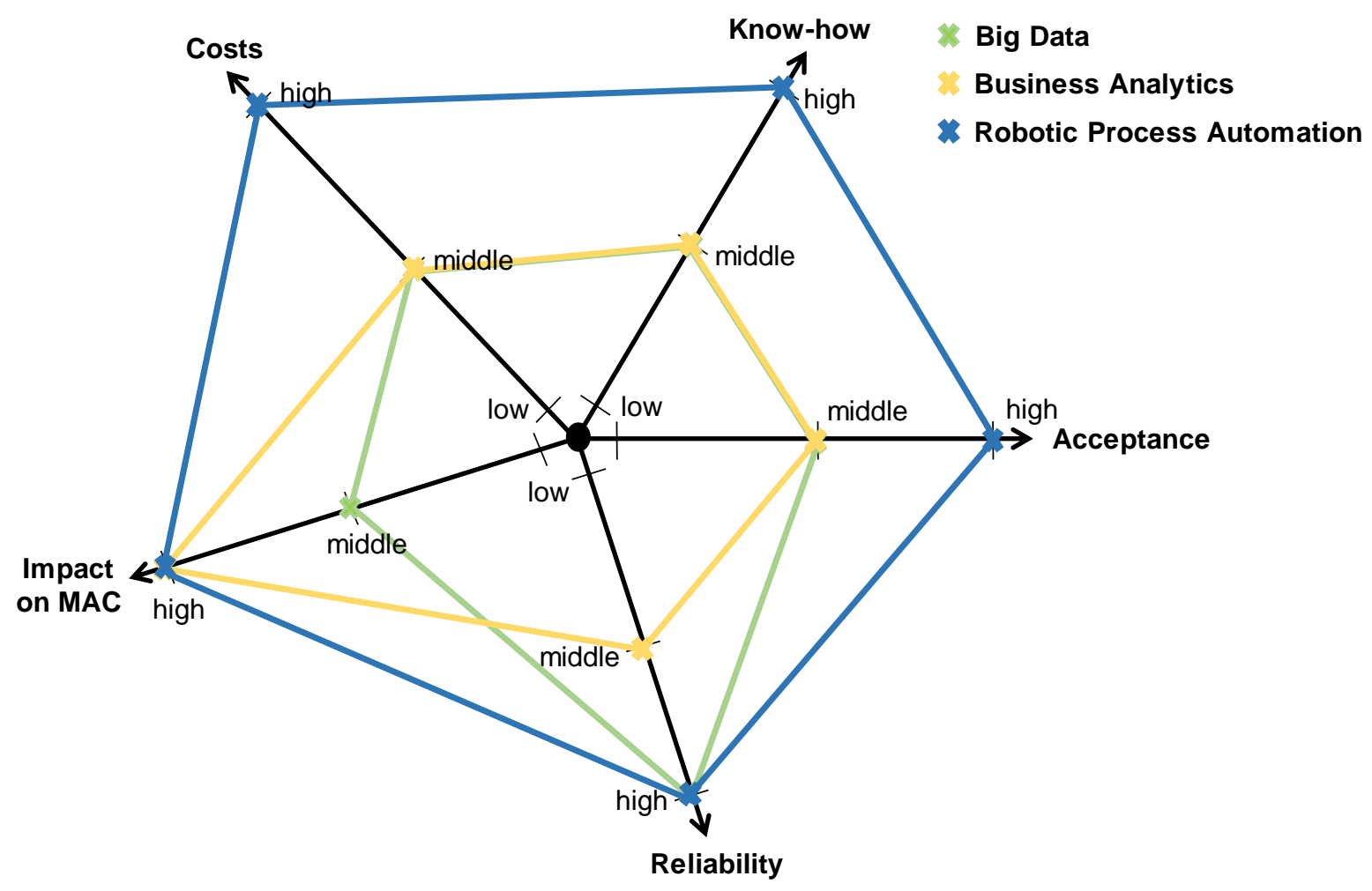

Figure 6: Radar Chart for Planning \& Budgeting (own image)

If Big Data models are implemented, the planning activities will change as they will become more efficient. This way, budgets can be combined with planning processes that are more flexible and are conducted in shorter time intervals. Yet, because of its more reactive nature, it requires some know-how to interpret this data. Moreover, the impact on basic MAC processes is significant.

Business Analytics models path the way to an increasingly independent planning process due to automation that has impacts on decision-making since trends and patterns can automatically be identified, e. g. in load process profiles. That leads to more objective planning and simplified risk detection. Therefore, a high impact is obvious as it leads to new data explanation that has not been recognized beforehand.

The effect of RPA on planning and budgeting processes is of mainly qualitative nature, it highly affects the quality of these while eliminating (human) mistakes plus decreasing the time it takes for the planning to be done. This way the load process profiles that have been detected using Business Analytics models, can be predicted for the future using RPA. Ergo, new business models can be identified and considered in future planning processes. 


\subsubsection{Forecasting}

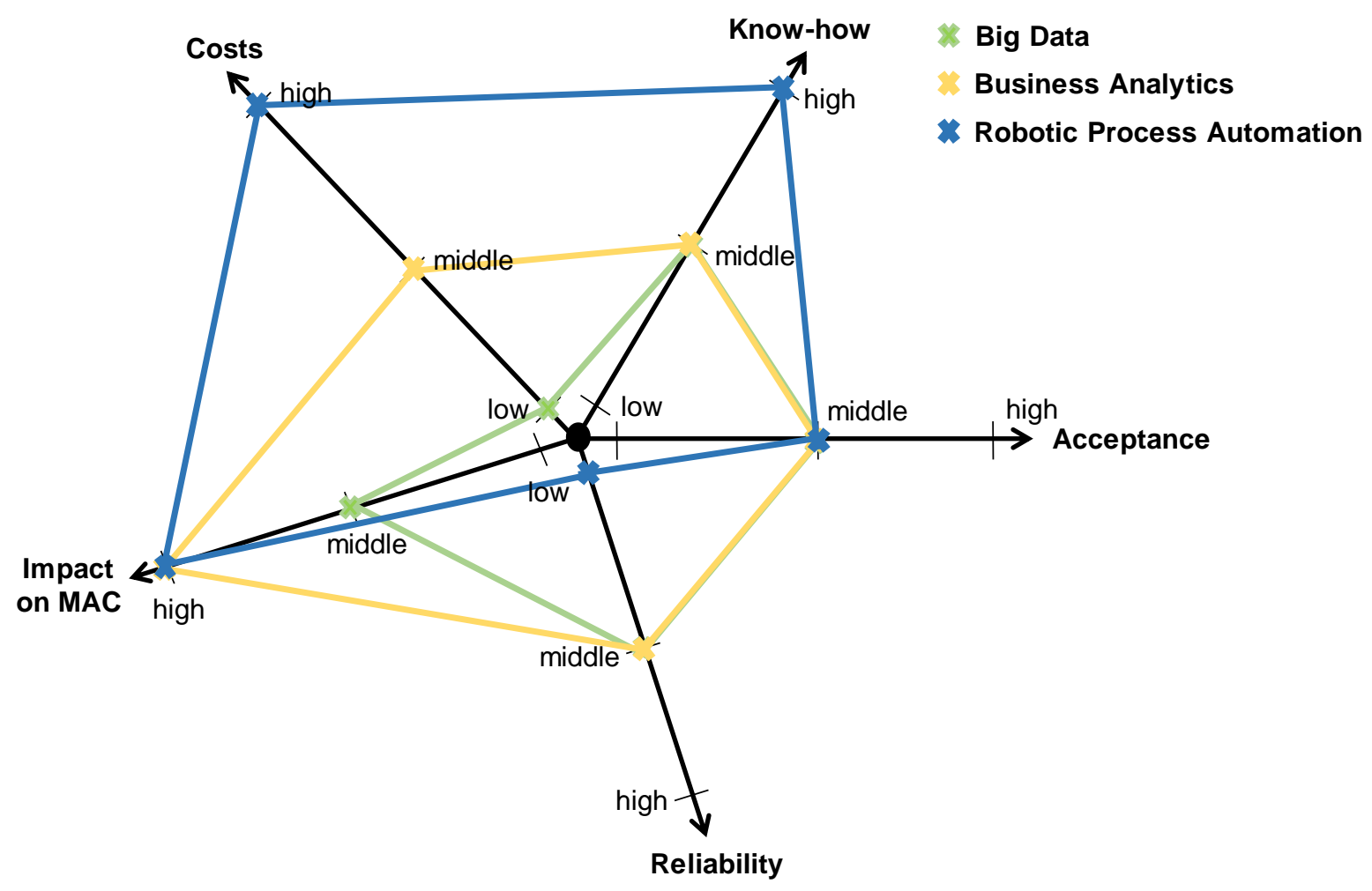

Figure 7: Radar chart for Forecasting (own image)

Because Big Data helps to provide forecasts with more accurate data, it is of average importance for the MAC department while the investment is fairly low. Because employees must understand which type of data is required and how to process it, it requires average knowknow. Since it features faster forecasting possibilities, it becomes more complicated to verify every result.

Business Analytics has the biggest impact on forecasting because of its' analytical methods which result in more efficient, precise and optimized forecasts. This is because of the potential discovery of patterns and new KPIs. Business Analytics will also have a big impact on MAC as a whole since it will enable management accountants to recognize new causal links and therefore deepen their analyses. In order to interpret the results, the process must be understood which requires average know-how and an average acceptance as the user cannot fully comprehend the models' results.

The usage of RPA in forecasting can be compared to reporting and planning: Forecasts can be performed more often, using up-to date data. Therefore, it is widely accepted in companies, yet due to the complex nature of this technology it can hardly be manually verified, is very costly and requires a lot of know-how. 


\section{Conclusion}

Energy Supply Companies must digitalize their MAC departments in order to act more resource-efficient and be prepared to face current as well as future challenges, instead of only modernizing business areas that have direct customer contact $(\mathrm{H} 3)$. This must happen in strict accordance to the individual requirements of the specific companies. In this respect, the impact of external factors cannot be waited for $(\mathrm{H} 2)$, but rather companies must act proactively in order to keep up with changing customer demands. Digital methods can help ESCs in sustainably adjusting their business models and acting in a more service-oriented manner with the final aim of offering products that go beyond the sole supply of energy, in order to delimit themselves from their competition and gain a competitive advantage.

In order to understand the possibilities digitalization holds $(\mathrm{H} 1)$, it has to be made clear to management accountants that digitalization can positively affect their work as it might facilitate and change the tasks over the years $(\mathrm{H} 4)$. Doing so will enable management accountants to concentrate on their core competences (analyzing and interpreting) rather than performing repetitive work. It must also be clarified to everybody involved, that digitalization does not necessarily lead to job losses as it rather prevents the company from being impacted by a lack of skilled employees. This is of special interest for energy suppliers as most of their municipal owners do not wish to suffer bad publicity for job cuts.

If a company has agreed on integrating digital methods, using a radar chart can help to identify which technology ought to be implemented when aiming for a predefined goal. A radar chart is particularly lucid as it allows a comprehensible display of technologies which are new to most companies. For example, if companies have sufficient funds and manpower, they can invest in more profound technologies (like RPA) compared to companies with small MAC departments which would need to hire external consultants to implement new technologies. If there is a severe mistrust against new technologies and reliability is a big issue, then technologies should not be implemented in forecasting but rather in reporting, making use of Big Data for example. In summary, using a radar chart enables management accountants to choose a technology for specific task.

It needs to be noted, that these results can only give a short introduction into this topic. Due to the dynamic market environment, new technologies must continually be added to the descriptive scope and concrete steps of implementing the various implementation possibilities are to be assessed. Furthermore, the qualitative scale of the radar chart into 'high', 'middle' and 'low' could be specified, e.g. into quantitative measures (such as concrete implementation costs).

On a next level, the accelerators and barriers identified should be matched with the respective implementation conditions within the relevant MAC functions in order to attune the benefits shown with the barriers. 


\section{Literature}

Bhimani, A. (2015). Exploring big data's strategic consequences. Journal of Information Technology, 30(1), 66-69.

Bolt, S. (2015). Big Data Analytics. Controlling, 27(11), 674-675. https://doi.org/10.15358/0935-0381-2015-11-674

Bundesnetzagentur \& Bundeskartellamt. (2020). Monitoringbericht 2019 [Monitoringbericht gemäß § 63 Abs. 3 i. V. m. § 35 EnWG und $\S 48$ Abs. 3 i. V. m. § 53 Abs. 3 GWB - Stand: 13. Januar 2020]. https://www.bundesnetzagentur.de/SharedDocs/Mediathek/Berichte/2019/Monitoringbericht_Energie2019.pdf?_blob=publicationFile\&v=6

Dierig, C. \& Wetzel, D. (2016). Dutzende deutsche Stadtwerke stehen vor der Pleite. https://www.welt.de/wirtschaft/article152480955/Dutzende-deutsche-Stadtwerke-stehenvor-der-Pleite.html

Doleski, O. D. (2017). Die Energiebranche am Beginn der digitalen Transformation: aus Versorgern werden Utilities 4.0. In O. D. Doleski (Hg.), Herausforderung Utility 4.0: Wie sich die Energiewirtschaft im Zeitalter der Digitalisierung verändert (S. 3-27).

Elsner, P., Sauer, D. U., Doetsch, C., Tübke, J. \& Weidner, E. (2015). Energiespeicher: Technologiesteckbrief zur Analyse "Flexibilitätskonzepte für die Stromversorgung 2050". https://www.researchgate.net/publication/300110577_Energiespeicher_-_Technologiesteckbrief_zur_Analyse_Flexibilitatskonzepte_fur_die_Stromversor-

gung_2050/link/570952b708aed09e916f9520/download

Fabritius, C. \& Fischer, M. (2019). Energiewende und Digitalisierung: Digitalisierte Netzwirtschaft als Baustein gesellschaftlicher Herausforderungen. https://www.pwc.de/de/energiewirtschaft/Studie_Digitalisierung_und_Energiewende.pdf

Gläser, J. \& Laudel, G. (2010). Experteninterviews und qualitative Inhaltsanalyse als Instrumente rekonstruierender Untersuchungen (4. Auflage). VS Verlag.

Harris, R. L. (2000). Information graphics: A comprehensive illustrated reference. Oxford University Press.

Irrek, W. (2004). Controlling der Energiedienstleistungsunternehmen. Eul Verlag.

Kelleher, J. D., MacNamee, B. \& D'Arcy, A. (2015). Fundamentals of machine learning for predictive data analytics: Algorithms, worked examples, and case studies. The MIT Press.

Kirschen, D. S. \& Strbac, G. (2004). Fundamentals of power system economics. Wiley.

Knapp, D. (2019). Preiskampf stürzt Energieversorger in die Pleite. https://www.nw.de/nachrichten/wirtschaft/22388776_Preiskampf-stuerzt-Energieversorger-in-die-Pleite.html

Landgrebe, J. (2006). Liberalisierung und Regulierungsmanagement im Telekommunikationsmarkt: Strategische Mitgestaltung regulatorischer Rahmenbedingungen durch die Marktteilnehmer in Deutschland. Gabler Edition Wissenschaft Markt- und Unternehmensentwicklung. Deutscher Universitätsverlag.

Langmann, C. (2019). Digitalisierung im Controlling. essentials. Springer Gabler; Springer Fachmedien Wiesbaden. https://doi.org/10.1007/978-3-658-25017-1

Legner, C., Eymann, T., Hess, T., Matt, C., Böhmann, T., Drews, P., Mädche, A., Urbach, N. \& Ahlemann, F. (2017). Digitalization: Opportunity and Challenge for the Business and Information Systems Engineering Community. Business \& Information Systems Engineering, 59(4), 301-308.

Manutiu, S. (2018). Digitalisierung im Controlling - Mehrwert durch Robotic Process Automation. Controlling, 30(3), 4-10.

Mayring, P. (2015). Qualitative Inhaltsanalyse: Grundlagen und Techniken (12. Aufl.). Beltz. 
Nasca, D., Munck, J. C. \& Gleich, R. (2018). Controlling-Hauptprozesse: Einfluss der digitalen Transformation. In R. Gleich \& M. Tschandl (Hg.), Haufe Fachbuch. Digitalisierung \& Controlling: Technologien, Instrumente, Praxisbeispiele (S. 73-88). Haufe-Group.

Oesterwind, D., Pfaffenberger, W. \& Hasse, D. (1996). Energieversorgung für eine offene Gesellschaft: Auf der Suche nach der besseren Lösung. etv Energiewirtschaft-und-TechnikVerlag.

Statistisches Bundesamt. (2008). Klassifikation der Wirtschaftszweige: Mit Erläuterungen [WZ 2008]. https://www.destatis.de/static/DE/dokumente/klassifikation-wz-20083100100089004.pdf 